oping world: history, philosophy and sociology of science and technology; social, gender and environmental issues in science and technology; and science and technology management. But, not surprisingly, the overall accent of the journal is firmly on science and economic development.

Even though it is edited from India, and has a bias towards things Indian, particularly in its review section, the journal casts a wide net. Latin America and Eastern Europe are well represented, and the main articles also carry abstracts in French and Spanish. And, despite its high standard of scholarship, the journal is designed to be accessible to a broad range of scientists working in R\&D fields. It should be on the essential reading lists of all scientists with an interest in developing countries.

Ziauddin Sardar, a consulting editor of Futures and visiting professor of science and technology policy at Middlesex University, is at 1 Orchard Gate, London NW9 6HU, UK.

\section{What's it all worth?}

\section{Environment and Development Economics}

Editor Charles Perrings

Cambridge University Press. 4/yr. $£ 84, \$ 126$

(institutional); $£ 44, \$ 66$ (personal); $£ 22$

(developing countries)

\section{Neil Adger}

It is the dominant world-view of applied social and natural scientists that the nature of economic preferences for natural resources and the environment is central to understanding why environmental change is occurring. Given the increasing scarcity of quality environments in all societies, and the apparent lack of success of regulators and individuals to stem the excesses caused by corporate, state and individual misuse of resources, insights from interdisciplinary research are required ever more urgently.

This journal provides evidence that analysis of these relationships is a burgeoning, policy-relevant field. In the first volume, applied papers examine such issues as the consequences of forest cover change; the intergovernmental economic institutions of the United Nations and their, at best, ambiguous role in sustaining the world's resources; epidemiology and environmental change; and economic incentives for conserving biological resources in contexts such as the ivory trade and wildlife hunting.

The target audience is primarily economists rather than other social scientists and natural scientists. Economists often argue that many decision-makers in government and other organizations are attuned to economists' ways of thinking and so they have a special place in the policy process, but not everyone believes what economists say.

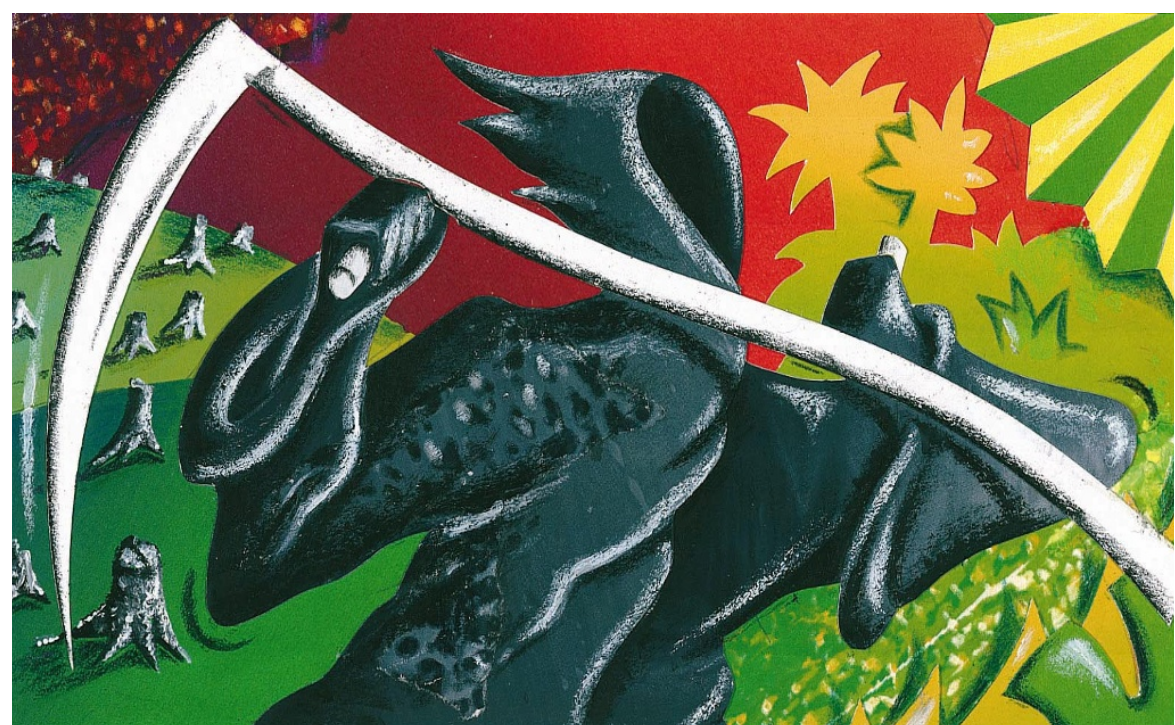

The journal plugs a hole in the literature, but it is one that has already been rapidly filling in the past few years with journals such as Environmental and Resource Economics and Ecological Economics, with which this journal shares many editorial board members.

The journal is attractively produced and contains both applied and theoretical papers and a policy forum section in each of the first year's issues. It is not in the prohibitively expensive category for some journals in this field. On the basis of the first volume, the journal deserves a place on the library shelves of universities and government ministries of planning and resources.

Neil Adger is at the School of Environmental

Sciences, University of East Anglia, Norwich, NR4 7TJ, UK.

\section{Physics matters}

\section{Studies in History and Philosophy of Modern Physics: Part B of Studies in History and Philosophy of Science}

Editors Jeremy Butterfield, Peter Gallison and Michael Redhead

Pergamon. 4/yr. NFl523, \$300

\section{David Goodstein and Judith Goodstein}

The history and philosophy of science were once largely the domain of former physicists. These were almost exclusively men who, before or after a career as research physicists, decided they could put their very considerable knowledge to other ends. Over the years, however, the profession gradually changed. More conventional historiography began to be heard, women entered the field, sciences other than physics began to be considered, and viewpoints such as social constructivism began to raise their (now much-maligned) heads. But, as all physicists know, the pendulum swings both ways. Studies in History and Philosophy of Modern Physics (SHPMP) is a triumphant return to the good old days.

In these pages there is no squishy biology, no feminist revisionism, no (well, almost no) social construction. This is hard-core internal history and philosophy of modern physics (essentially twentieth-century, although the prospectus allows modern to mean anything after the mid-nineteenth century). Relativity and quantum mechanics reign supreme.

Of course, the broad outlines of those histories are well known, but there are always new details and considerations to bring to light. Equations are a plus, or at least not a minus. It's heavy-going, and don't bother even to try reading it if you haven't taken your graduate courses in physics. But if you have a taste for this sort of thing, and if you've felt a little dispossessed since, say, the 1950s, you may just have found a new home.

In the Alice in Wonderland world of scholarly publishing, SHPMP does fill a void. Not for the readers, who are more or less irrelevant, but for authors, who need an outlet for this kind of material. The idea is that scholars get paid and promoted by their employers, the universities, provided that they can find someone to publish their material, so the universities can buy back for their libraries the scholarly output they paid for in the first place. Why all this works is a mystery, but it does, and SHPMP will fit right in.

The articles have a uniformity of style that indicates careful editing. The scholarly machinery is exquisite, with footnotes (in small type) often occupying more space than the text (in larger type). The content returns physics solidly to centre-stage, and deals with ideas and equations, not flesh and blood. Articles of up to 10,000 words - or even more in special circumstances - are accepted. If that's what you've been looking for, look no further. This is a journal that says: at the end of the twentieth century, physics still matters.

David Goodstein (Department of Physics) and Judith Goodstein (Department of History) are at the California Institute of Technology, Pasadena, California 91125, USA. 